\title{
Corrosion resistance of steel reinforcement in polymer silicate shyngizite concrete
}

\author{
Irina Sokolova ${ }^{1, *}$ \\ ${ }^{1}$ Moscow State University of Civil Engineering Yaroslavskoe shosse, 26, Moscow, 129337, Russia
}

\begin{abstract}
Polymersilicate concrete is used for structures of industrial buildings in many industries, where production processes form an acidic wet- gas operating environment. The lightweight polymer silicate shungizite concrete, proposed by the author for external walls, can also be attributed to these materials. The polymersilicate composition is based on the components of schungite and schungizite. The composition also included liquid glass, sodium silicofluoride and furyl alcohol. These ingredients are usually adopted for polymersilicate concrete. Previously, the author carried out the research of physical and mechanical properties of the composition. The components based on schungite and schungizite were chosen because of their high acid resistance. The issue of the corrosion resistance of reinforcement in light polymer-silicate concrete has not been studied enough. This article presents the results of investigations of the corrosion resistance of steel reinforcement in polymer silicate shungizit concrete. The investigations were carried out in an airy environment of high humidity and in solutions of sulfuric acid of various concentrations. After the established time limits for corrosion testing, the corrosion of reinforcement in samples was not observed. Such a result was obtained due to the dense structure of the material and high acid resistance of the constituent components on the basis of schungite and shungizite. There is no need for additional protection of the concrete surface to prevent corrosion of the reinforcement in it . The author recommends the use of the material for reinforced structures of external walls exposed to an acidic wet- gas operating environment.
\end{abstract}

\section{Introduction}

The author's scientific research is related to the issue of increasing the durability of the outer walls of buildings with an aggressive production environment. Building structures of many industries are exposed to the destructive effects of an aggressive technological environment. This is non-ferrous metallurgy, chemical, petrochemical industry, textile industry, food industry, a number of agricultural sectors. The stylobate parts of the external walls of buildings located on major highways are constantly exposed to the negative effects of the aggressive environment that is created by the exhaust gases. From 15 to $75 \%$ of buildings and structures are exposed to the destructive effects of atmospheric and industrial aggressive environments. Protection of building structures from destruction under the

*Corresponding author: i.socolova@yandex.ru 
impact of the aggressive environment is an urgent task. Technological media containing sulfur dioxide, hydrogen sulfide, hydrogen chloride, nitrogen oxides are widespread. High humidity of most industries enhances the corrosion processes in building structures. Groups of aggressive gases depending on their type and concentration are shown in table 1.

Table 1. Groups of aggressive gases depending on their type and concentration.

\begin{tabular}{|c|c|c|c|c|}
\hline \multirow{2}{*}{ Denomination } & \multicolumn{4}{|c|}{ Concentration, $\mathbf{~ k g} / \mathbf{~ m}^{3}$ for gas groups } \\
\cline { 2 - 5 } & A & B & C & D \\
\hline sulfur dioxide & from 0 to 0.5 & over 0.5 to & over 10 to & over 200 to \\
& & 10 & 200 & 1000 \\
\hline hydrogen sulfide & from 0 to & over 0.01 to & over 5 to 100 & over 100 \\
& 0.01 & 5 & & \\
\hline hydrogen chloride & from 0 to & over 0.05 to & over 5 to 10 & over 10 to 100 \\
\hline nitrogen oxides & 0.05 & 5 & & \\
\hline & from 0 to 0.1 & over 0.1 to 5 & over 5 to 25 & over 25 to 100 \\
\hline
\end{tabular}

When the humidity of the internal air is from 50 to $60 \%$ and the temperature is over 12 to $24 \mathrm{oC}$ (normal operating conditions) the degree of aggressive effect of Group A gases on reinforced concrete is non-aggressive, group B is slightly aggressive, group $\mathrm{C}$ is medium-aggressive and group $\mathrm{D}$ is highly aggressive. When the humidity of the internal air is from 60 to $75 \%$ and the temperature is over 12 to $24 \mathrm{oC}$ (humid operating conditions) the degree of aggressive effect of Group A gases on reinforced concrete is slightly aggressive, group B is medium-aggressive, group $\mathrm{C}$ is highly aggressive and group D is highly aggressive.

A material has been proposed be the author, that meets the requirements for external walls operating under conditions of exposure to acidic humid gas aggressive environments. The material is a polymer silicate composition with schungite and schungizite components. The following premises contributed to the selection of this composition. Polymersilicates are used for the manufacture of acid-resistant structural elements. Shungite is a mineral with high acid resistance [1]. The inertness of shungite in relation to aggressive environments is explained by its structural features. Shungite is a crystalline carbon modification, similar in structure to anthracite. Shungite has a high chemical resistance to sulfuric, nitric, hydrochloric, and acetic acids. Lightweight shungizite aggregate is obtained by roasting shungite. The glass phase ( $\mathrm{Al}-\mathrm{Fe}-\mathrm{Si}$ ) in shungizite is $85 \%$. The acid resistance of shungizite in sulfuric acid is $97 \%$, in hydrochloric acid - 98\%. Shungizit gravel has low water absorption and high frost resistance. Shungizit gravel is less heat-conducting than expanded clay gravel. The chemical composition of shungite and shungizite according to the results of laboratory studies are shown in table 2 .

Table 2. The chemical composition of schungite and schungizite, $\%$ by weight.

\begin{tabular}{|c|c|c|}
\hline Name of components & Shungite & Shungizit \\
\hline $\mathrm{SiO} 2$ & 55.25 & 60.11 \\
\hline $\mathrm{Fe} 2 \mathrm{O} 3$ & 15.28 & 14.80 \\
\hline $\mathrm{Al} 2 \mathrm{O} 3$ & 18.57 & 15.57 \\
\hline $\mathrm{CaO}$ & 3.06 & 2.78 \\
\hline $\mathrm{MgO}$ & 3.60 & 3.60 \\
\hline $\mathrm{So} 3$ & 0.16 & 0.16 \\
\hline $\mathrm{K} 2 \mathrm{O}$ & 1.17 & 0.48 \\
\hline $\mathrm{Na} 2 \mathrm{O}$ & 3.15 & 2.62 \\
\hline
\end{tabular}

There is experience of using shungizit concrete on cement binder for the outer walls of civil buildings. The author has developed polymer silicate compositions with schungizite 
gravel and finely ground schungite and schungizite fillers. The physical and mechanical properties of the compositions are investigated. There were studied the characteristics that determine the functional purpose of the material: acid resistance, weather resistance, water permeability, water absorption, sorption humidity, frost resistance. The coefficient of thermal conductivity of the material is determined. A polymer silicate solution has been developed. In the polymer silicate solution, finely ground schungite and schungizite are used. These components are waste products of shungizite gravel. The use of these components will improve the environment. The research results can be found in the articles $[1,2,3]$. The safety of reinforcement in reinforced concrete is of great importance. Experience has been gained in ensuring the durability of reinforcement in structures made of heavy polymer silicate concrete. Structures of heavy polymer silicate reinforced concrete are successfully used in acidic environments at non-ferrous and ferrous metallurgy enterprises, as well as in the chemical industry. Studies are being carried out to ensure the protection of reinforcement in concrete on porous aggregates. The research results are given in [4-9]. Reinforcing corrosion in polymer silicate schungizite concrete has not been previously investigated.

\section{The object of the study}

The safety of reinforcement in concrete has a significant impact on its durability. This is especially important when the material is exposed to an aggressive production environment. The object of the study is the corrosion resistance of steel reinforcement in polymer-silicate shungizit concrete. Table 3 shows the properties of the composition developed by the author. These data are important in terms of predicting the protective properties of the material in relation to reinforcement.

Table 3. Properties of the Polymer Silicate Composition.

\begin{tabular}{|c|c|}
\hline Properties & Numerical values \\
\hline dry material density, $\mathrm{kg} / \mathrm{m}^{3}$ & 1030 \\
\hline open capillary pore volume, $\%$ & 10.0 \\
\hline pore saturation factor, $\%$ & 16.7 \\
\hline volume of conditionally closed pores, $\%$ & 47.8 \\
\hline intergranular voidness, $\%$ & 2.2 \\
\hline sorption humidity, $\%$ at a relative humidity of $80 \%$ & 2.15 \\
\hline water resistance coefficient (test period -360 days) & 0.83 \\
\hline weather resistance (test period -360 days) & 0.94 \\
\hline frost resistance & $\mathrm{F} 75$ \\
\hline $\begin{array}{c}\text { chemical resistance coefficient in } 24 \% \mathrm{H}_{2} \mathrm{SO}_{4} \text { (test period }-360 \\
\text { days) }\end{array}$ & 0.94 \\
\hline
\end{tabular}

The rate of the corrosion process depends on the density of concrete, its moisture content, and the presence of aggressive substances on the surface of the reinforcement. Reinforcement corrosion does not occur in water-saturated concrete. The flow of oxygen to the surface of the reinforcement stops. In underwater structures, reinforcement is stored for a long time. At a constant relative humidity (60-70\%), reinforcement corrosion also does not occur. In wet gas environment, the corrosion of reinforcing steel depends on the thickness of the moisture film on its surface and the composition of the air. In conditions of low values of relative humidity (up to $40-50 \%$ ), a moisture film is adsorbed on the surface of the material. This film is so thin that it essentially represents a transitional state of aggregation between a solid and a liquid. This film does not have the properties of an electrolyte and does not create conditions for the occurrence of electrochemical corrosion. 
As the relative humidity of the surrounding air increases, the film thickness on the metal surface increases. With a film thickness of microns or more, moisture acquires the properties of "free water" and becomes electrically conductive. This process begins to develop at a relative humidity of $70-75 \%$. In this case, due to a decrease in the rate of oxygen supply to the metal surface, the corrosion process slows down. Investigations of reinforcement corrosion in light polymer-silicate shungizit concrete were carried out by direct corrosion tests. Polished and fat-free steel rods with a diameter of $4 \mathrm{~mm}$ and a length of $120 \mathrm{~mm}$ were taken for testing. The rods were laid in concrete samples measuring $160 \times 40 \times 40 \mathrm{~mm}$ during the molding process . The thickness of the protective layer of concrete was 10 and $25 \mathrm{~mm}$. Samples were placed for two years in acidic (5\% and $24 \%$ $\mathrm{H} 2 \mathrm{SO} 4)$ and aqueous media after 28 days of hardening in air-dry conditions. Other samples were tested in air-dry conditions $(\mathrm{t}=20-25 \mathrm{oC}, \phi=45-55 \%)$, and in an air environment with air humidity of $75 \%$ and $97 \%$ for 4 years.

\section{Results}

The results of testing are shown in Table 4.

Table 4. Corrosion resistance of steel reinforcement in polymer silicate shungizit concrete.

\begin{tabular}{|c|c|c|c|c|c|}
\hline \multirow{2}{*}{$\begin{array}{c}\text { Test } \\
\text { conditions }\end{array}$} & $\begin{array}{c}\text { Test } \\
\text { period, } \\
\text { years }\end{array}$ & $\begin{array}{c}\text { Theight loss, } \\
\mathbf{g} / \mathbf{m}^{2}\end{array}$ & $\begin{array}{c}\text { depth of } \\
\text { penetration of } \\
\text { acid into } \\
\text { concrete, } \mathbf{~ m m}\end{array}$ & $\begin{array}{c}\text { weight loss, } \\
\mathbf{g} / \mathbf{~ m}^{2}\end{array}$ & $\begin{array}{c}\text { Tepth of } \\
\text { penetration of } \\
\text { acid into } \\
\text { concrete, } \mathbf{~ m m}\end{array}$ \\
\cline { 3 - 6 } & 2 & not detected & 10 & not detected & 25 \\
\hline $\mathrm{H}_{2} \mathrm{O}$ & 2 & not detected & 10 & not detected & 25 \\
\hline $\begin{array}{c}4 \% \mathrm{H}_{2} \mathrm{SO}_{4} \\
\text { solution }\end{array}$ & 2 & not detected & 6 & not detected & 6 \\
\hline $\begin{array}{c}24 \% \mathrm{H}_{2} \mathrm{SO}_{4} \\
\text { solution }\end{array}$ & 2 & & \\
\hline
\end{tabular}

Visually, the condition of the samples was satisfactory in all of the environments after the established test time. The samples had a flat surface. The formation of cracks on the surface of the samples was not observed. Opening of the samples showed that the reinforcement was well preserved in all samples. The surface of the reinforcement had a characteristic metallic luster without any signs of corrosion. No mass loss of the rods was observed. The absence of reinforcement corrosion in air-dry conditions and in an air environment with a relative humidity of $75 \%$ can be explained by the alkaline nature of the concrete medium $(\mathrm{pH}=11.0-11.5)$ and the absence of an electrically conductive film on the metal surface. Under these conditions, the sorption humidity of the material is $1-1,5 \%$ by weight [2]. No signs of corrosion were observed in samples tested at $97 \%$ relative humidity. The absence of corrosion in this case can also be explained by the alkaline nature of the concrete medium. In addition, the pores with sorption moisture impeded the access of oxygen to the metal surface. The absence of reinforcement corrosion in the samples tested when completely immersed in water can be explained by the alkaline nature of the concrete medium $(\mathrm{pH}=11.5)$. The second reason is that the concrete, up to the reinforcement, was saturated with moisture that did not allow oxygen to pass to the surface of reinforcement. In this case, the aqueous extract from shungizit sand and finely ground schungizit filler had a $\mathrm{pH}=11$. Alkaline aggregate was involved in neutralizing penetrating acid. When opening samples tested in a sulfuric acid solution with a concentration of $4 \%$, it was found that moisture penetrated the concrete and reached the reinforcement. Concrete layer located 
near reinforcement had an alkaline reaction. A thin outer layer of concrete with a thickness of $2.5-5.0 \mathrm{~mm}$ had an acid reaction of the medium. Steel rods were in good condition. In the samples stored in sulfuric acid at a concentration of $24 \%$, the formation of a dark contour with a thickness of 5-7 mm along the perimeter of the samples was observed. This layer had an acidic reaction $(\mathrm{pH}=1)$. The concrete layer sealed with Furyl alcohol polycondensation products significantly slowed the penetration of acid into the samples. The rest of the concrete had an alkaline reaction of the medium $(\mathrm{pH}=10.0-11.5)$. The concrete layer directly adjacent to the reinforcement had a moisture content of about 2.0 $2.5 \%$ by weight. Under these conditions, the formation of an electrically conductive film on the metal surface is difficult.

\section{Conclusions}

As a result of the research it was established that polymer silicate shungizit concrete can be reinforced with steel reinforcement. There is no need for additional protection of the concrete surface to prevent corrosion of the reinforcement in it. The author recommends the use of polymer silicate shungizit concrete for reinforced structures of external walls exposed to an acid wet-gas aggressive environment. The thickness of the concrete protective layer for steel reinforcement must be at least $20 \mathrm{~mm}$.

\section{References}

1. I.V. Sokolova, Izvestiya vysshih uchebnyh zavedenij. Tekhnologiya tekstil'noj promyshlennosti 4(370), 258-262 (2017)

2. I.V. Sokolova, Inzhenernyj vestnik Dona 1(48), 173 (2018)

3. I. Sokolova, E3S Conference, 02038 (2019) DOI: https://doi.org/10.1051/e3sconf/20199102038

4. N.K. Rozental', Pervichnaya zashchita betonnyh $i$ zhelezobetonnyh konstrukcij. Dolgovechnost' stroitel'nyh konstrukcij. Teoriya i praktika zashchity ot korrozii (Centr ekonomiki i marketinga, 2002)

5. V.F. Stepanova, Zashchita armatury ot korrozii v betonah na poristyh zapolnitelyah (OOO Bumazhnik, Moscow, 2016)

6. N. Vatin, N. Lavrov, G. Loginov. MATEC Web of Conferences. 2016. 73. DOI:10.1051/matecconf/20167301006.

7. N. Vatin, A. Sinelnikov, M. Garifullin, D. Trubina. Applied Mechanics and Materials. 2014. 633-634. Pp. 1037-1041. DOI:10.4028/www.scientific.net/AMM.633-634.1037

8. S. Nikolskiy, N. Vatin, O. Pertseva. Journal of Applied Engineering Science. 2015. 13(1). Pp. 11-18. DOI:10.5937/jaes13-6553.

9. S. Ognjenovic, R. Donceva, N. Vatin. Procedia Engineering. 2015. 117(1). Pp. 544550. DOI:10.1016/j.proeng.2015.08.210. 